\title{
On Exploration and Reformation of the Political Counselor Team
}

\section{in Dezhou University}

\author{
Qinglin Shen \\ Dezhou University, Dezhou 253023, Shandong, China \\ E-mail: sqldzyzz@163.com
}

Received: December 7, $2010 \quad$ Accepted: December 22, $2010 \quad$ doi:10.5539/ass.v7n5p247

\begin{abstract}
The team of the political counselors in Dezhou University is a young and energetic team and a main force for student education and management in the critical period of reform and development. Strengthening the construction of the counselor team can improve the overall student management and lay a solid foundation for cultivating high-quality talents. This text gives an analysis of the status quo of the political counselor team in Dezhou University and tries to present some suggestions on how to build and reform it.
\end{abstract}

Keywords: College, Counselor, Team, Building

Counselors are the bones to the work of the ideological and political education for college students and an indispensable force to ensure the sustainable and healthy development of higher education. Strengthening the counselor team building is of great significance to promote the ideological and political education in colleges and universities.

\section{The analysis of the status quo of the political counselor team in Dezhou University}

Dezhou University was set up in 2000. For several years, the student work has been in exploration and trial stage, particularly the work concerning the counselor team building. The Students Affair Division has summed up good practices of other colleges and universities, and made some effective measures to stabilize the number of the counselors to promote the development of student work.

There are 17477 students and 102 part-time and full-time counselors in Dezhou University now. The teacher -and-student ratio is 1:170, as meets the demand of the Ministry of Education. The full-time counselors are 85, including the secretaries (and deputy secretaries) of each department in charge of student affairs, student counselors and the Youth League secretaries. There are 17 part-time counselors including the relevant staff of Student Affairs Division and the Youth League.

Let me analyze the team structure. In terms of political structure, among all the counselors there are 87 Party members, 28 Youth League members, as can basically guarantee that the student affairs can adhere to taking the Party leadership as the core and ideologically keep in line with the Central Committee. As for age structure, 36 counselors are in the bracket of aging 20 to 30 , accounting for $35 \%$ of the total number of counselors and 59 counselors are in the bracket of aging 30 to 40 , accounting for $57 \%$ of the total number, which forms a reasonable orderly system of succession. The whole team is dynamic and energetic and can accept new things as soon as possible and ensure to pass the work experience on to keep the work stable and continuous. As for the professional positions, there are 27 junior counselors, accounting for $26 \%$ of all, 55 people of the intermediate professional title, accounting for $54 \%$ of the total and 20 people of the senior titles, accounting for $20 \%$ of the total. This can meet the demand of the student management and scientific research and provide a reasonable platform for the innovation and development of the whole team. On the basis of the schooling structure, among all the counselors 3 received college education, accounting for 3\%, 61 won bachelor's degree, accounting for $60 \%$ of the total, 27 won master's degrees, accounting for $26 \%$ of the total. The schooling structure can make it possible for the counselors and student to make a successful communication and exchanges. Furthermore, it can ensure that the counselors can accept a higher level of training. As for the working time of the counselors, 71 people have worked less than 5 years, accounting for $70 \%$ of the total number, 31 people has worked for 5 to 10 years, accounting for $30 \%$ of the total. Most counselors have worked for a shorter period. So to them, the student work is still a new field, which also provides them with a free development platform and space for innovation and development of student work. 


\section{Strengthening the professional team construction and increasing the total working capacity}

According to the above data analysis, student work team in Dezhou University is a relatively young team. Counselors are vibrant and full of energy, but lack of experience. Their abilities to deal with complex issues need improving. In particular, the full-time counselors work in the first line of the student affairs all the year round. Their working levels and abilities will have a direct impact on the overall student work. How to improve the work of the full-time counselors is important to the problem of how to strengthen the team building of student work.

To enhance the working abilities of the full-time counselors, we should make measures in the following three aspects.

2.1 Exchanges should be strengthened so that counselors can learn from each other, offer reference for one another and make a joint improvement

In order to facilitate the communications among counselors, the Student Affairs Division first opens a forum in the office network to provide a platform for internal communications. Secondly, working group of counselors is set up in Dezhou University to provide a faster and more convenient communication among counselors. External platform for communication is also provided for counselors. Even if they go out for studying, they can learn about what is happening to the students in the school, as contributes a lot to the continuity of the work for the students. Thirdly, saloons are held to provide opportunities for them to have a face-to-face communication, which can strengthen the cohesion of the counselor team, help them clarify the work ideas and find better way to work.

\subsection{Enhance the training and broaden the vision horizons to improve the working ability of counselors}

The training of counselors should be held in two ways, one is the internal training. Teachers who have engaged in students work for many years can be invited to give lectures about the train of thinking and way of how to solve problems. The other is the external training, in particular, the counseling and training classes held by authorities at all levels because such classes generally involve many colleges and universities. In the training process, the counselors can combine the explanations of the experts and the practical situation in Dezhou University to explore the new and constructive way of thought of the student work.

\subsection{Accentuate learning and perform deep practice to improve the ideological and political quality}

In the spare time, as a student worker he or she should keep accentuating learning in mind. We should not only learn the theoretical knowledge involving the student work, but also learn about the mental health of the students, career planning, employment policy, safety knowledge, injuring handling, urgent danger prevention and so on and so forth so that we can avoid in the work hurting the students because we don't know that policies concerned. At the same time, we must pay attention to carrying on practice, making research and investigation, truly understanding the requirements of the students, knowing about how the students think to perform our work purposefully.

\section{Give full play to the function of part-time counselors and teachers in charge of the classes to lay a solid basis for the student work}

3.1 Accentuate the assessment and management on the part-time counselors to promote the healthy development of counselor team

According to the resolution of College Work Council of Shandong Province, workers from the student affair division and the some members of the Youth League are all classified into the team of part-time counselors. However, as the part-time counselors, they can not enjoy the same treatment as the full-time counselors can, which may affect their enthusiasm.

In order to improve the work enthusiasm of part-time instructors, fully embody the principles of unity of responsibility, rights and benefits, and ease the problem of inadequate number of full-time counselors, we should improve the benefit of the full-time counselors but meanwhile, we should also strive to think about the part-time counselors. They should be put into the team of the full-time counselors and the appropriate assessment criteria should be developed to determine the appropriate treatment so as to stimulate the work enthusiasm of the part-time counselors.

After completing the assessment for the part-time counselors, we should give due consideration on allowances, promotion, and assessment of professional titles according to the result of the assessment. At the same time, the assessment result should be put into the overall assessment on the students work to promote the healthy development of part-time counselor team. 


\subsection{Build a good team of teachers in charge of classes to promote the harmonious development of the student work}

A teacher in charge of a class or a class director is the direct educator, organizer or instructor for the students, a necessary and useful supplement to the student work team. Strengthening the management of the team of the class directors, establishing an efficiency class director team is of great significance to improve the quality of education, guide the healthy growth of the students and improve the overall level of the student work.

The key to accentuate the class director team mainly lies in resolving the problem of the cooperation between the counselors and class directors, who must know distinctly about their own duties. The counselors should decompose the task, make plans and report it to the leading group after receiving the task. The leading group will make an assignment in the classes and ask the class directors to implement it. If there is something wrong in the cooperation between the counselors and the teachers in charge of classes, the student work will be affected a lot. Strengthening the building of the class director team needs further training and guiding. The work of the class directors should be in line with the student work. The internal training is for class directors and the external training is for counselors, as is carried out by the student work leading group of the department. Each department, according to its own features and the actual situation of the class director team in the department, implements purposefully the education and training activities to enhance work efficiency and capacity of the class directors and better the overall student work.

\section{Strengthening the research and innovation of the counselor team and improve their theoretical knowledge}

4.1 Strengthen researches and surveys; deeply understand the students' actual situation to carry out work purposefully

No investigation, no right to speak. If a worker for students does not go into the grass roots of the students, he or she will never know what the students think or want and the work will only remain theoretical. And the students won't understand and support him or her. Therefore, enhancing the investigation and research of student work is the inexhaustible motive force to make it progress, and the source of innovation and development of student work. Strengthening investigation and research should abide by some certain principles. One is that the content of investigation should be closely related to the learning and living of the students. It can not be divorced from the actual situation of the students. The second is that a survey should have different subjects. Different survey content should have different and appropriate subjects. Those who truly have a say in the investigation must be chosen as the subjects. The third is that the findings of the surveys should be analyzed matter-of-factly. Without subjective color, the problem can emerge. The fourth is that, to deal with the investigation result should be based on the analysis to take the actual situation of the school into consideration and adopt the appropriate solution. The fifth, as to the subsistence of the survey results, the form of survey is needed to give a summary and the problems found in the process of investigation needs analyzing. Especially for the uncompleted investigating tasks, further analysis is needed to find the problem and analyze the reasons, contributing to the correction to future investigation.

\subsection{Strengthen the work of innovation and propose the new ideas and methods for the student work}

Innovation is the soul for a nation's progress and growing momentum for the student work. Improving the innovation capacity and theoretical level of the student work team does not mean the number of papers and the times of doing research work, but lies in whether the existing problems in the student work are seriously considered and whether promoting the development of student work is taken as their goal.

For the counselors who have engaged in the student work for quite a long term, innovation is more difficult than they want to do because the changing students will bring different problems to them. That is to say, counselors should constantly change their ways of thinking. They can not consider the questions in the same way, as is another important reason for them to reform the student work.

The creative work needs knowing about the actual situation of the students, mastering the psychological activities of the contemporary students, and analyzing the major problems troubling the students and the causes in order to find the appropriate countermeasures. The second is to strengthen the study to meet the demands of development of the times in knowledge. The third is to strengthen the exchanges among the institutions. Good experiences and practices should be drawn on to avoid crooked roads while in work. The fourth is to strengthen the thinking and conclusion about the work. We should learn to be good at finding problems at work, sum up the lessons, and try to make a reform and innovation in work.

The construction of counselor team is a long process. It requires the joint efforts of all counselors and 
management divisions to provide a good platform for the healthy development of the counselor team. Furthermore, more concerns from the whole society are needed to make the counselors work securely, happily and independently, as can fully stimulate the enthusiasm and creativity of the counselors, make them play their leading role in the process of student growth to make greater contributions to cultivate qualified college students and socialist construction talents.

\section{References}

Chen, Jianbo. (2004). Research on fuzzy assessment means of the work by the college counselors. Journal of Lishui University, 10.

Liu, Hongda, Yan, Lily and Zhong, Wenrui. (2007). On the basic aspects of constructing professionalized college counselor team. Journal of Higher Correspondence Education, 03.

Lu Yan. and Meng, Wei. On the dominant role of College Counselors. Educational Theory and Practice.

Tao, Li. and Li, Jun. (2007). On strengthening the construction of college counselors. China Construction Education, 07.

Yin, Guiming. (2006). On the work features and requirements of College counselors. Journal of Cangzhou Teachers College, 03. 